\title{
PROGRAMAÇÃO NO SCRATCH NO ENSINO FUNDAMENTAL: UMA POSSIBILIDADE PARA A CONSTRUÇÃO DE CONCEITOS MATEMÁTICOS
}

\author{
Bruno Silveira Corrêa - PPGEMat/UFRGS - brunocorrea.mat@ gmail.com \\ Márcia Rodrigues Notare - PPGEMat/UFRGS - marcia.notare@ufrgs.br
}

\begin{abstract}
Resumo
Neste artigo analisam-se as contribuições do software Scratch no desenvolvimento de conceitos matemáticos que se apresentam durante o processo de programação. A pesquisa foi desenvolvida com oito alunos de $8^{\circ}$ ou $9^{\circ}$ anos do Ensino Fundamental de uma escola da rede privada de Porto Alegre. Trata-se de uma pesquisa cujo objetivo é contribuir para o desenvolvimento de práticas que envolvam ambientes de programação que possibilitem a construção de conceitos matemáticos. Para análise dos dados foi utilizada a teoria do desenvolvimento cognitivo de Jean Piaget, que permitiu compreender o desenvolvimento do pensamento do aluno, do fazer ao compreender, e a teoria Construcionista de Seymour Papert. Os resultados apontam para o desenvolvimento de habilidades matemáticas desenvolvidas durante a manipulação do software em atividade de programação de forma coletiva ou individual, além da apropriação da linguagem de programação do software Scratch.
\end{abstract}

Palavras-chave: Conceitos Matemáticos; Scratch; Programação no Ensino Fundamental, Fazer e Compreender.

\section{SCRATCH PROGRAMMING IN ELEMENTARY SCHOOL: A POSSIBILITY FOR CONSTRUCTION OF MATHEMATICS CONCEPTS}

\begin{abstract}
In this article, we analyze the contributions of Scratch software in the development of mathematical concepts that are presented during the programming process. A research was developed with eight students from 8th or 9th grade of elementary school in a private school in Porto Alegre. This research aims to contribute to the development of practices involving programming environments that allow the management of mathematical concepts, using Jean Piaget's approach to data analysis and cognitive development theory in search of development of the studant thinking, of the doing to the understanding, and also Seymour Papert's Constructionist theory. The results point to the development of some mathematical skills that can be executed in any software collectively or individually, besides the appropriation of the Scratch software programming language.
\end{abstract}

Keywords: Mathematical Concepts; Scratch; Programming in Elementary School, Doing and Understanding.

\section{Introdução}

Seymor Papert, um dos criadores da linguagem de programação LOGO, acreditava ser possível utilizar uma linguagem de computação para pessoas comuns, especialmente crianças. Dessa forma, visava possibilitar experiências que ele mesmo já havia vivenciado ao iniciar seu contado com computadores.

Foi nessa situação que eu pensei sobre computadores e crianças. Eu estava brincando como uma criança e experimentando uma vulcânica explosão de

V. $17 \mathrm{~N}^{\mathrm{o}}$ 3, dezembro, 2019

criatividade. Por que o computador não poderia proporcionar a uma criança o DOI: RENOTE 
mesmo tipo de experiência? Por que uma criança não poderia brincar como eu? O que teríamos que fazer para tornar isso possível? (Papert, 2008, p.44)

Nesse sentido, vemos o uso da programação no software Scratch, que em comparação com o software SuperLogo 3.0, tem interface gráfica mais intuitiva e mais atrativa para crianças com a utilização de blocos, parecidos com os blocos do Lego ${ }^{\circledR}$, como uma forma do aluno aprender conceitos matemáticos e computacionais a partir da experiência da programação, tendo o computador como uma ferramenta ativa e criativa para o interesse na aprendizagem desses conceitos, dando a possibilidade dos alunos estarem participando de forma efetiva da construção do seu conhecimento.

Nesse contexto, esse artigo apresenta um recorte de uma pesquisa de mestrado, a qual buscou responder à pergunta: Como são desenvolvidos conceitos matemáticos na programação de animação de personagens no software Scratch? Para isso, foi elaborada uma oficina e oferecida para estudantes do oitavo e do nono ano do Ensino Fundamental. Na atividade apresentada e analisada nesse artigo, os alunos, organizados em grupos, tiveram como objetivo programar ações para um personagem utilizando o Scratch online.

A análise dos resultados está apoiada na teoria do desenvolvimento cognitivo de Piaget, que ajudou a compreender o desenvolvimento do pensamento do aluno em ambiente de programação como ferramenta para o desenvolvimento de conceitos matemáticos.

\section{Referencial Teórico}

De acordo com Basso e Gravina (2012), o computador vem tendo papel cada vez mais fundamental em nossas vidas. Porém, as facilidades e possibilidades proporcionadas pelo computador e pela internet nos fazem refletir sobre a necessidade de incorporar as tecnologias na rotina escolar, pois "elas também influem nas formas pensar, de aprender, de produzir" (Basso, Gravina, 2012, p. 12). Segundo Valente (1993), a linguagem LOGO, desenvolvida no Massachusetts Instituteof Technology (MIT), Boston E.U.A., pelo professor Seymour Papert, tem como objetivo criar uma linguagem para nos comunicarmos com o computador, tendo duas raízes para explorar seus aspectos de aprendizagem: a computacional, que tem como característica a exploração de atividades espaciais, fácil terminologia e capacidade de criar novos procedimentos, e a pedagógica, que está fundamentada no construtivismo piagetiano, na qual a criança aprende diversos conceitos matemáticos a partir de experiências do cotidiano, interagindo com objetos do ambiente em que ela vive. Sendo assim, o construcionismo de Papert defende a construção do conhecimento mediante a interação entre aluno e ferramenta, nesse caso, o computador.

Em ambientes de programação, uma das características principais é a ideia de erro conceitual, no qual "o erro deixa de ser uma arma de punição e passa a ser uma situação que nos leva a entender melhor nossas ações e conceitualizações" (Valente, 1993, p. 23). Caso o programa não produza o efeito esperado, significa que o conceito utilizado não foi empregado de forma correta (e talvez ainda não tenha sido compreendido), o que permite uma análise desse erro, possibilitando uma oportunidade de avançar no entendimento do conceito envolvido no problema proposto e, consequentemente, desenvolver novas estruturas e habilidades matemáticas.

Nesse contexto, buscamos na teoria do desenvolvimento cognitivo de Piaget apoio para analisar o desenvolvimento de conceitos matemáticos em atividades de programação no software Scratch. Buscamos também evidenciar o papel da tecnologia, em específico a programação, no desenvolvimento do aluno na construção de novas estruturas para a resolução de problemas. 


\title{
2.1 Programação e a Aprendizagem de Matemática
}

Segundo Resnick (2007), a rápida mudança existente no mundo atual requer que as pessoas encontrem soluções criativas para problemas inesperados. $\mathrm{O}$ quanto sabemos e o que sabemos já não é o único ponto a ser avaliado para o sucesso, mas sim a capacidade de pensar e agir de forma criativa. Essa perspectiva em que vivemos é denominada por Resnick como "Sociedade Criativa".

O que vemos na sala de aula, hoje, nos faz pensar se a escola ajuda os alunos a desenvolverem-se criativamente. Mesmo alunos com bom rendimento escolar, que aprendem a resolver classes específicas de problemas, muitas vezes não conseguem adaptar o seu conhecimento a uma nova situação, e essa habilidade é inevitável em um mundo que enfrenta rápidas e inesperadas mudanças. Nesse sentido, para Resnick (2007) as novas tecnologias desempenham um papel importante para a sociedade, já que, além de acelerar as mudanças acentuando a necessidade de pensamento em diversos aspectos da vida das pessoas, também dispõem de um potencial inerente para a colaboração do desenvolvimento de pensadores criativos, sendo uma delas a programação.

Pea (1987) já defendia que as tecnologias, em particular o computador, estão influenciando nossos métodos e, mais importante, nossos objetivos, o que reflete na mudança do que são considerados objetivos da compreensão e do pensamento matemático referente aos processos educacionais que estão sendo encaminhados. Em relação ao uso da tecnologia na Educação e sobre o impacto do computador na relação entre humano e máquina, Pea (1987, p. 95, tradução do autor) afirma que

\begin{abstract}
[...]é consistente com questões baseadas em uma imagem bidirecional que outros educadores e pesquisadores de matemática [...] estão fazendo, tais como: Quais são as novas coisas que você pode fazer com tecnologias que você não poderia fazer antes? Ou que não eram práticas para fazer? Quando você começa a usar a tecnologia, que coisas totalmente novas você percebe que podem ser possíveis? Por "imagem bidirecional" quero dizer que os computadores não afetam apenas as pessoas, mas as pessoas afetam os computadores. Isso é verdade em dois sentidos. Em certo sentido, todos nós afetamos os computadores e as oportunidades de aprendizado que eles oferecem aos alunos na educação pela forma como os interpretamos e pelo que definimos como práticas apropriadas com eles; à medida que essas interpretações mudam com o tempo, alteramos os efeitos que os computadores podem ter mudando o que fazemos com eles.
\end{abstract}

Nessa concepção, na qual o computador pode ter uma alteração de efeitos a partir do que é feito com ele, Valente (1993) afirma que o uso dos computadores na Educação tende para diferentes perspectivas a partir de suas novas modalidades de uso, deixando de ser uma "máquina de ensinar" para ser vista como uma mídia educacional que promove o desenvolvimento do pensar do indivíduo: "o computador passa a ser uma ferramenta de complementação, de aperfeiçoamento e de possível mudança na qualidade de ensino" (Valente, 1993, p. 6). Essa mudança se deve à nossa condição de vida, que é dominada pela informação e pelos processos rápidos e imperceptíveis que estão ocorrendo todos os dias.

\subsection{A teoria do pensamento cognitivo de Piaget na programação}

A partir da perspectiva do uso da programação como ambiente que pode desencadear processos de aprendizagem, o uso das tecnologias digitais na Educação Matemática vem sendo pensado como uma ferramenta potente na qual o aluno pode utilizar para criar e pensar Matemática. Nesse contexto, propomos uma investigação analisada à luz da teoria do desenvolvimento cognitivo de Piaget, que busca V. $17 \mathrm{~N}^{\circ}$ 3, dezembro, 2019 RENOTE DOI: 
compreender de que forma a criança se desenvolve e o conhecimento progride da passagem da ação pura para o pensamento que é efetuado a partir das tomadas de consciência. Segundo Piaget (1978),

[...] existem ações complexas, embora de êxito precoce, que apresentam todas as características de um saber, mas apenas de um "savoirfaire" (saber fazer), e que a passagem dessa forma prática de conhecimento para o pensamento se efetuava através de tomadas de consciência, sem se restringir de forma alguma, a uma espécie de esclarecimento, mas consistindo numa conceituação propriamente dita, isto é, numa transformação dos esquemas de ação em noções e em operações [...] (Piaget, 1978, p. 10).

Dessa maneira, podemos dizer que o desenvolvimento do compreender se inicia pela ação, que busca atingir um objetivo sem se preocupar com a compreensão dos meios nos quais foram utilizados para realizá-lo, até o nível em que essas ações são realmente compreendidas. Assim, dizemos que a passagem da prática para a conceituação parte da ação para o saber como agir.

Segundo Piaget (1978) a conceituação se torna uma influência resultante da ação que se efetua a partir de consciências posteriores. A conceituação passa a ser um processo posterior à ação, tendo sua influência a partir de determinado nível. "O que a conceituação fornece à ação é um reforço de suas capacidades de previsão e possibilidade, em presença de uma dada situação, de dar um plano de utilização imediata" (Piaget, 1978, p. 174). Dessa forma, o estabelecimento da compreensão sobre a ação possibilita uma capacidade de antecipação do indivíduo em relação a uma determinada situação, o que favorece a capacidade de escolha entre os diferentes meios de resolução, permitindo assim uma programação da ação a partir da conceituação.

A aprendizagem por meio da programação muitas vezes é caracterizada pela tentativa e erro. Para que o programa execute uma ação é necessário que o indivíduo que deseja realizar o procedimento dê um comando para alcançar um determinado objetivo. Quando esse objetivo não é alcançado, o indivíduo pode implementar outro comando para que a ação seja executada de forma correta a partir da análise do erro, fazendo com que o agente programador, a partir das ações, "estabeleça fronteiras entre a prática ("o que fazer para conseguir?") e o sistema de seus conceitos ("por que as coisas se passam dessa maneira?")" (Piaget, 1978, p. 174). Assim, quando há a compreensão da ação, o sujeito tem a capacidade da antecipação, nesse caso, o indivíduo poderá antecipar a execução do programa, estabelecendo os comandos necessários de forma correta e não aleatória, passando do "fazer", para o "compreender".

[...] fazer é compreender em ação uma dada situação em grau suficiente para atingir os fins propostos, e compreender é conseguir dominar, em pensamento, as mesmas situações até poder resolver os problemas por elas levantados [...] (Piaget, 1978, p. 176).

Desta forma, a tomada de consciência fundamenta-se na passagem da compreensão prática para uma compreensão conceitual, tornando o sujeito capaz da teorização antes da ação, e não mais apenas ação, promovendo, assim, o raciocínio a partir da abstração.

\section{Metodologia e Proposta}

A pesquisa apresentada nesse artigo teve como objetivo analisar como se desenvolvem conceitos matemáticos a partir da atividade de programação da animação de um personagem no Scratch. A coleta de dados foi realizada em uma escola particular 
de Porto Alegre situada no centro da cidade, na qual atende alunos de $1^{\circ}$ a $9^{\circ}$ ano do Ensino Fundamental. A escola possui um espaço virtual que foi utilizado para a realização e coleta dos dados da pesquisa. $\mathrm{O}$ espaço virtual, conhecido na escola como Sala de Informática, é composto de 31 computadores cujo sistema operacional é Windows 7.

Para realizar a pesquisa, foi elaborada uma oficina de programação de jogos com o software Scratch, a qual se constituiu o espaço para a coleta dos dados. Como sujeitos da pesquisa, foram selecionados oito alunos, três do $8^{\circ}$ ano e cinco de $9^{\circ}$ ano, sendo duas meninas e seis meninos. As atividades da oficina foram realizadas em dez encontros. Porém, nesse artigo, analisaremos alguns episódios ocorridos nos dois primeiros encontros, sendo cada encontro de uma hora para cada grupo. Os alunos foram divididos em dois grupos de quatro componentes. Nesse trabalho, teremos como sujeitos para análise o primeiro grupo, no qual foi dividido em duas duplas. Os alunos selecionados para a oficina apresentavam perfil favorável à resolução de desafios e tinham disponibilidade para participar no turno inverso do horário habitual das aulas.

Os encontros foram gravados em áudio a partir de um celular que ficava junto aos alunos durante a realização das atividades. Outros meios para a coleta dos dados foram o caderno de campo, utilizado pelo pesquisador para anotar as situações existentes, cadernos dos grupos de estudantes, nos quais eles planejaram e anotaram alguns procedimentos, e fotos, que foram tiradas para captar as imagens das construções dos alunos nas diversas situações que ocorriam durante o processo. Por fim, foram utilizadas as produções dos alunos que constavam em seus cadastros do site, podendo observar a produção final realizada no Scratch.

No primeiro encontro, tivemos como proposta a escolha de um ator, disponibilizado pelo Scratch, para posteriormente movimentá-lo no palco. Para a programação da movimentação do ator no palco, foi enfatizada a importância do "evento", para que o computador pudesse iniciar a ação desejada, assim como a importância de utilizar o comando correto para que o computador o execute a animação da forma desejada. Nesse processo, os alunos desenvolveram esquemas básicos de programação, que permitiram dar continuidade ao trabalho.

No segundo encontro, propomos utilizar um novo ator para deixar a programação um pouco mais elaborada. Para isso, os alunos deveriam mudar as fantasias do ator para animá-lo, utilizando o comando espere. As análises estão apresentadas na seção a seguir.

\section{Descrição e análise praticados resultados}

Nos primeiros momentos da oficina, foi solicitado às duplas que escolhessem um ator disponível no Scratch e que o movimentassem no palco (ressaltamos que esses alunos não tinham experiência com programação). $O$ objetivo inicial era a experimentação de blocos para programar ações para o personagem. Para isso, foi necessário discutir com os estudantes sobre a comunicação entre programador e máquina, a partir de ordens precisas, detalhadas e organizadas, de forma que o programador fornecesse instruções corretas para o computador. A categoria Evento foi muito explorada para que a relação entre programação e execução fosse estabelecida.

Foi possível observar nas ações de uma das duplas, identificados por A e M, um processo de exploração e ambientação dos recursos do software. Como hipótese inicial da dupla para o movimento do ator, o bloco que caracteriza o evento "quando a tecla espaço for pressionada" é encaixado ao bloco "mova 15 passos", o que fez o ator mover-se para a direita. Em uma ação experimental, o bloco "gire sentido anti-horário 20 graus" foi encaixado com os demais e fez com que ocorresse um movimento de 
looping na tela, situação na qual A e M não conseguiram explicar. Dessa forma, observa-se nesse momento um processo de ação pura, na qual os blocos são testados para um determinado fim, mesmo que esse fim seja uma forma provisória de resolver o problema e que ainda não seja totalmente compreendido pelos alunos A e $\mathrm{M}$.

Como um novo desafio, foi solicitado às duplas que movimentassem o ator em diferentes sentidos no palco. O objetivo dessa atividade exigia dos alunos a ideia de localização, compreendendo os movimentos do ator no palco de forma consciente e controlada. Como ações iniciais da segunda dupla, identificados por I e S, são escolhidos os comandos "quando a tecla seta direita for pressionada" e "quando a tecla seta esquerda for pressionada" para os movimentos de direita e esquerda. Vemos aqui que os alunos já identificaram um padrão para que o computador realize as funções solicitadas e, dessa forma, as ações utilizadas nesse momento foram previamente pensadas, tomando consciência da necessidade de um evento para que a programação ocorra e antecipando suas ações.

Em ambos os eventos, os alunos adicionaram o comando "mova 10 passos". Porém, no momento de execução, ao pressionar, tanto seta esquerda, como seta direita, o ator movimentava-se sempre para a mesma direção, o que surpreendeu os alunos e provocou um desequilíbrio momentâneo. Isso porque os alunos acreditavam que a tecla "seta direita" movimentaria o ator para a direita e que a tecla "seta esquerda" movimentaria o ator para esquerda. Observando as ações de I e S, o aluno A questiona se o número digitado dentro do bloco de "mova $\mathrm{n}^{\mathrm{o}}$ passos" não deveria ser negativo. $\mathrm{O}$ aluno S observou os blocos "adicione 10 a x" e "adicione 10 a y" e comentou: "Ah, entendi! $O$ x é o comprimento e o y é a altura", apontando para o seguinte espaço da tela (Figura 1). Nesse momento, a ideia de sistema de coordenadas cartesianas (conceito ainda desconhecido) está sendo construída por $\mathrm{S}$, a partir de ações e experimentações no ambiente de programação.

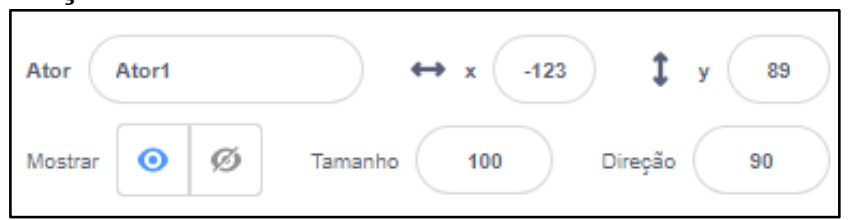

Figura 1 - Informações na interface do Scratch. Fonte: Acervo pessoal

$\mathrm{Na}$ tentativa de movimentar o ator e explorando os blocos de comandos, o aluno $\mathrm{S}$ descobre que também poderia utilizar o comando "vá para $\mathrm{x}:\left(\mathrm{n}^{\circ}\right) \mathrm{y}:\left(\mathrm{n}^{\mathrm{o}}\right)$ ", e assim o faz, arrastando os blocos para a área de programação. Ao executá-lo, os alunos perceberam que estavam realizando um comando que estabelecia um local fixo para o ator cada vez que eles pressionavam a tecla programada, ou seja, o ator movimentava-se para o local de coordenadas $(\mathrm{x}, \mathrm{y})$ na primeira vez que a tecla era pressionada. Porém, nas tentativas seguintes, o ator continuava na mesma posição (x, y) e os alunos precisaram analisar a situação, compreender o significado do comando utilizado, tanto do ponto de vista da programação, quanto do ponto de vista do conceito matemático inerente a ele, para identificar o erro e solucioná-lo, tornando o processo operatório. Explorando as possibilidades de comandos e a movimentação do ator no palco (novamente nível da ação), os alunos descobriram que o ator tem uma posição no palco que é definida por x e por y, sendo que cada lugar do palco tem uma posição x e y diferente e específica. $\mathrm{O}$ conceito de posição no plano cartesiano está sendo explorado e, aos poucos, construído em ação. Nesse momento, os alunos puderam, a partir da programação e análise dos resultados, compreender a ideia de coordenadas cartesianas e par ordenado como um par de números ordenados que localizam um ponto no plano. Mesmo que os alunos não tenham conseguido atingir o objetivo inicial (dar movimento contínuo para o ator no palco), descobriram uma nova possibilidade para movimentar o V. $17 \mathrm{~N}^{\circ}$ 3, dezembro, 2019 RENOTE DOI: 
ator para uma posição definida do palco, a partir da compreensão do papel de suas coordenadas x e y.

Na exploração do comando "adicione $10 \mathrm{a}$ x", pudemos observar as tomadas de consciência dos alunos sobre a distribuição dos números inteiros no eixo das abscissas, pois analisaram as possibilidades de substituir valores em $\mathrm{x}$, tanto positivos, como negativos e descobriram os respectivos resultados. Dessa forma, o palco pode ser conceituado como um plano com coordenadas, observando que x representa o quanto deve ser adicionado para o ator andar para a direita e o quanto deve ser retirado para que ele vá para a esquerda. Ao serem questionados sobre o movimento vertical do ator, eles descobriram que devem usar o comando "adicione 10 a y" e "adicione -10 a y", podendo assim também movimentar o ator para cima e para baixo.

É interessante observar a mudança das ações dos estudantes, na programação do movimento horizontal do ator, passando para um processo de conceituação, que mesmo ainda apoiado na ação de testar como o ator iria para cima ou para baixo, já estava se consolidando. A partir do momento em que os alunos compreenderam o movimento vertical do ator, podemos concluir que, a partir dos esquemas de ações utilizados nos movimentos, os sujeitos compreenderam a movimentação total do ator no palco, sabendo antecipadamente como fazer para que o ator se movimente para a direita, para a esquerda, para cima e para baixo, não havendo mais a necessidade de testar blocos. Decorrente disso, desencadeou-se um processo de compreensão de conceitos matemáticos como plano cartesiano, eixos coordenados e par ordenado.

Podemos perceber nesse processo de tentativa e erro para movimentar o ator no palco que os estudantes tiveram uma conduta apoiada em ações para verificar os movimentos do ator a partir dos comandos selecionados, sem saber quais seriam os resultados de suas ações. A partir dessas ações, os sujeitos puderam compreender como cada bloco influenciaria no movimento do ator. A partir de então, já não era mais necessário testar blocos para saber como o ator poderia se movimentar na horizontal ou na vertical. Logo, os alunos passaram a um processo de compreensão e um domínio do problema de movimentação no palco, chegando ao nível da conceituação do que foi feito, transformando esquemas de ações em operações. Sendo assim, podemos caracterizar os conceitos representados pelos alunos como uma tomada de consciência, passando do processo de ação pura para uma conceituação (Piaget, 1978).

Para o segundo encontro, foi proposto o desafio de inserir animação aos personagens no palco com troca de fantasia. Analisando as ações da dupla I e S, cujo objetivo era movimentar um morcego no placo, observamos a exploração de novos blocos para a programação. Utilizando o evento "quando a bandeira verde for clicada", seguido do comando "sempre", lembrando das discussões do encontro anterior e identificando um possível padrão para iniciar o algoritmo, os alunos perceberam na categoria Aparência do bloco "mude para a fantasia", utilizando-o dentro do comando "sempre". A proposta da dupla era que o movimento do morcego tivesse quatro fantasias para completar um ciclo de movimentos de bater as asas, repetindo-se posteriormente o mesmo ciclo.

Ao clicar em bandeirinha verde, os alunos I e S perceberam que nada acontecia. Nesse momento, foi necessário discutir com os alunos que a mudança estava acontecendo, porém, na velocidade de processamento do computador. Assim, eles perceberam a necessidade de incluir um tempo determinado entre uma fantasia e outra, para que fosse possível observar a animação do personagem. Dessa forma, a dupla identificou na lista de comandos o bloco "espere" e o utilizou entre uma fantasia e outra. Na primeira tentativa, os alunos colocaram o comando "espere" apenas entre as duas primeiras fantasias. Ao executar o procedimento, perceberam que deveriam encaixar o 
comando "espere" entre todos os blocos de fantasias. Após algumas experimentações para definir um tempo adequado, a dupla chegou ao algoritmo de programação ilustrado na Figura 2.

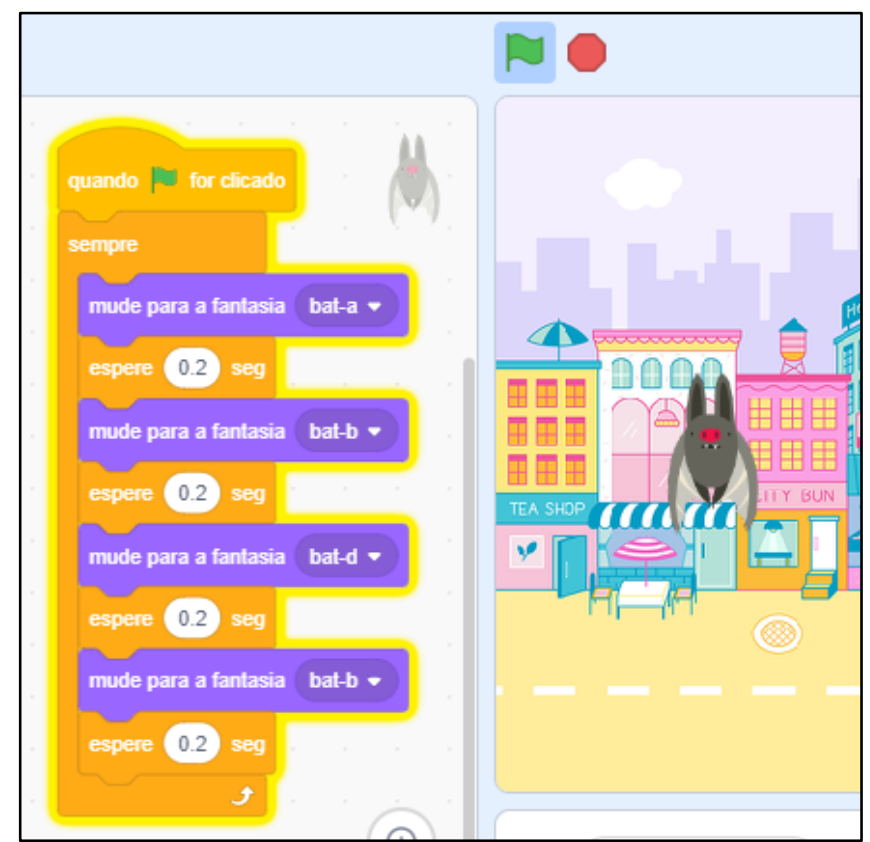

Figura 2 - Algoritmo para animação do ator utilizando o comando "espere". Fonte: Acervo pessoal

Como os alunos não sabiam de antemão o que aconteceria ao executar o procedimento, tiveram que partir para as ações de tentativa e erro. Segundo Piaget (1978), compreender em ações faz parte do fazer, em um grau suficiente para atingir um propósito. Dessa forma, ações podem ser repetidas até que o sujeito consiga dominar, em pensamento, as mesmas situações, passando a compreender o processo.

Da mesma forma que ocorreu com a primeira dupla, o procedimento da dupla A e M não apresentava animação ao ser executado (o objetivo da dupla era abrir e fechar as pinças de um caranguejo). Novamente, foi apresentado o comando "espere", para que fosse possível observar a troca de fantasias e obter sucesso na animação. Na Figura 3, temos a programação da animação do personagem dos alunos A e M.

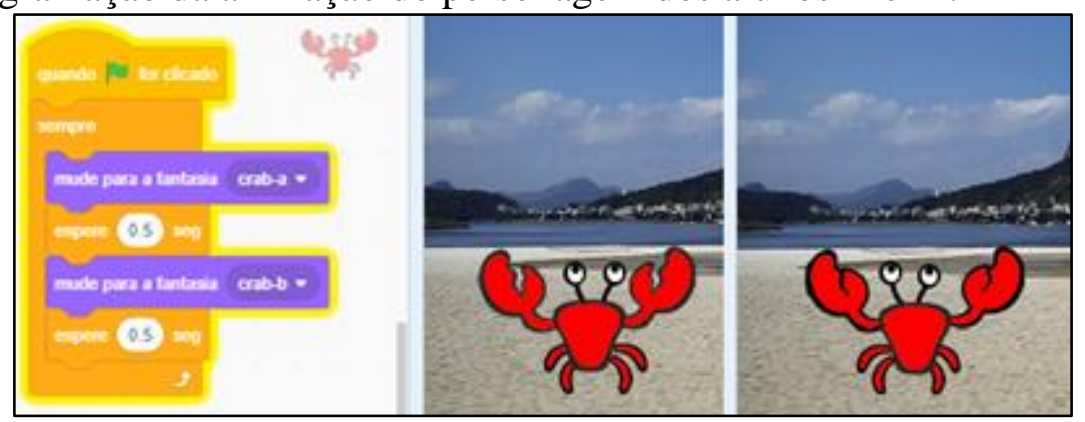

Figura 3 - Algoritmo para a animação do ator e sua animação, dupla A e M. Fonte: Acervo pessoal

Verificamos nesse processo, no qual incluímos ambas as duplas, que o uso do padrão inicial para a programação foi importante para desencadear uma sequência de ações que foram responsáveis para que os alunos conseguissem chegar a um fim, visto que durante o processo de encaixar o comando "espere" entre as mudanças de fantasia foi se conceituando como um processo necessário para que animação fosse possível, ou seja, os sujeitos tomaram consciência de que, para conseguir executar a animação desejada para um algoritmo que desempenhe essa função, é necessária a utilização do comando "espere" entre todos os blocos de troca de fantasia. Consideramos que os alunos, a partir das ações de programar a animação no primeiro momento, em que a V. $17 \mathrm{~N}^{\circ}$ 3, dezembro, 2019 RENOTE DOI: 
troca de fantasias acontecia na velocidade do processador do computador, perceberam a necessidade de outro fator para resolverem o problema. Observar a tentativa de encaixar o comando "espere" entre os blocos das fantasias nos mostra as ações para chegar ao êxito como um saber fazer, proporcionando uma reflexão durante as ações, transformando os esquemas das ações em noções conscientes, proporcionando um pensamento a partir da forma prática de conhecimento (Piaget, 1978).

$\mathrm{Na}$ última atividade, analisamos as ações da dupla I e $\mathrm{S}$. A atividade tinha como proposta animar o personagem durante a movimentação no palco. Como o objetivo era movimentar o personagem (novamente o morcego), a dupla utilizou o evento "quando tecla seta para a direita for clicada", juntamente com o bloco "adicione 10 a x". Destacamos que, dessa vez, os alunos sabiam de antemão exatamente quais blocos encaixar para que o personagem se movimentasse para a direita, o que fortalece a hipótese de conceituação do primeiro encontro e que os conceitos de plano cartesiano e par ordenado foram compreendidos pelos sujeitos, tornando-se operatório. Nesse sentido, a conceituação de coordenadas no sistema de coordenadas cartesianas ultrapassa a ação, possibilitando uma antecipação dos comandos sem a necessidade de testes, evidenciando a capacidade de previsão e de planejamento da ação.

No momento de executar o procedimento, ao pressionarem o botão seta direita, os alunos foram surpreendidos com o seguinte resultado: o morcego movimentou-se os dez passos para a direita e, posteriormente, fez os movimentos de animação, não se movendo mais para a direita. Questionados sobre o porquê o personagem teve aquele comportamento, a dupla imediatamente identificou que a sequência de comandos pedia para o personagem movimentar 10 passos para direita apenas uma vez e, em seguida, animar com a troca de fantasias, não necessitando mais ir para a direita para fazer o movimento. Os alunos testaram e observaram também que, retirado o bloco "sempre", cada vez que a tecla seta direita fosse pressionada o personagem iria fazer aquela sequência de movimentos até o fim, tendo que esperar o movimento completo descrito na sequência para que executasse novamente.

Depois de algumas experimentações, a dupla decidiu utilizar novamente o evento "quando bandeira verde for clicado", utilizando os algoritmos do encontro anterior para movimentar o morcego, apresentando um evento para cada direção de movimento (Figura 4).

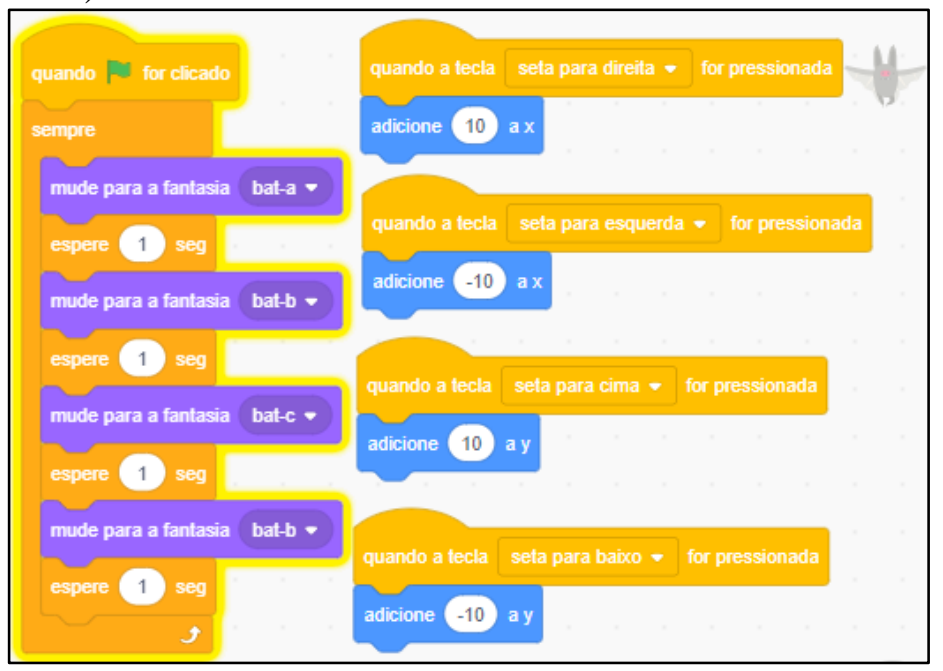

Figura 4 - Algoritmos com evento paralelos de animação e movimento. Fonte: Acervo pessoal.

Consideramos dois pontos interessantes a se destacar: o primeiro é o uso do comando "espere" na programação. É possível compreendê-lo a partir da alteração do número de vezes que se pretende repetir as ações (nível da ação), até que houve uma 
compreensão de seu conceito, considerando um recurso importante a ser explorado em atividades futuras. O segundo ponto refere-se ao número de algoritmos, que poderiam ser generalizados, de modo a se obter apenas um algoritmo para um único propósito. Esse aspecto foi explorado em encontros futuros.

Percebemos que o êxito ao completar as tarefas foi, por vezes, a partir das ações de exploração, tentativa e erro, observando problemas a serem solucionados. A partir de ações que pudessem colaborar para a realização das tarefas, os alunos puderam reconhecer e generalizar alguns conceitos matemáticos (e de programação) que foram compreendidos durante o processo.

\section{Considerações finais}

Os dados coletados durante a pesquisa buscam responder à questão norteadora: Como são desenvolvidos conceitos matemáticos na programação de animação de personagens no software Scratch? Para responder a essa pergunta, foi necessário observar as ações dos sujeitos durante o processo de programação para posteriormente observar o produto final. Nessa perspectiva, observando as análises dos dois encontros, percebemos avanços no desenvolvimento de conceitos matemáticos relativos ao sistema de coordenadas cartesianas nas ações dos sujeitos.

Percebemos que, com auxílio do software Scratch e seus blocos de encaixe, os alunos puderam observar com mais fluidez os possíveis fenômenos que suas ações realizavam. Puderam a partir de ações de experimento, conceituar o plano cartesiano, fazendo com que um ator se movimentasse no palco, observando os efeitos dessas ações e levando a uma tomada de consciência desses conceitos, abstraindo esses conceitos para aplicá-los em situações que o software proporcionava.

Os resultados dessa pesquisa foram considerados satisfatórios, pois tivemos uma resposta positiva dos alunos em relação à prática, tanto no sentido de aprendizagem como no sentido de estímulo para se pensar em matemática. Destacamos que os sujeitos da pesquisa não tinham conhecimento de programação nem de sistemas de coordenadas cartesianas. É esperado que esse trabalho possa motivar outros professores e pesquisadores a utilizarem a tecnologia como ferramenta de aprendizagem e objeto de estudo, tendo em vista que as tecnologias tem por objetivo modificar a forma de se pensar matemática.

\section{Referências}

GRAVINA, M. A., BASSO, M. V. A., Mídias Digitais na Educação Matemática. In: GRAVINA, M. A. et al. (org.) Matemática, Mídias Digitais e Didática - tripé para formação do professor de Matemática. Porto Alegre: Evangraf, 2012.

PAPERT, S. A máquina das Crianças: repensando a escola na era da informática. Tradução de Sandra Costa. Ed. Rev. Porto Alegre: Artmed, 2008.

PEA, R. Cognitive technologies for mathematics education. In A.H. Schoenfeld (Ed.), Cognitive Science and Mathematics Education. p. 89-122, 1987. Hillsdale: Lawrence Erlbaum. <http://web.stanford.edu/ roypea/RoyPDF\%20folder/A41_Pea_87b.pdf>Acesso online em 28 dez. 2018.

PIAGET, J. Fazer e Compreender. São Paulo: Melhoramentos, Editora da Universidade de São Paulo, 1978.

RESNICK, M. Sowing the seeds for a more creative society. Learning and Leading with Technology, p. 18-22, 2007.

VALENTE, J. A. Diferentes usos do computador na educação. Computadores e Conhecimento: repensando a educação, p. 1-23, 1993. Disponível em: $<$ http://www.nied.unicamp.br/sites/default/files/livros/livro-computadores-econhecimento.pdf > Acesso online em 03 abr. 2018. 